\title{
Sexuality in Europe. A Twentieth Century History.
}

\author{
Cambridge University Press, New York, 2011., 230 str.
}

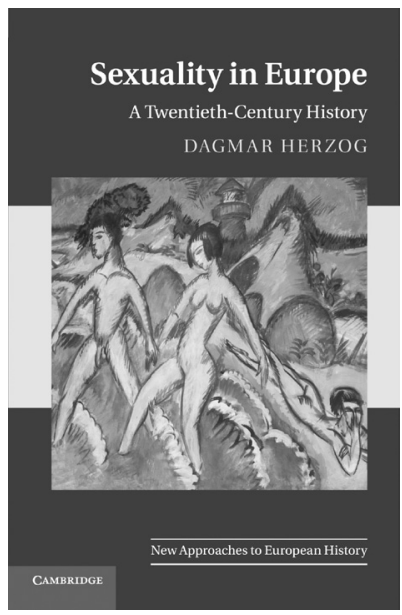

Sexuality in Europe. A Twentieth Century History. (,Seksualnost u Europi. Povijest dvadesetoga stoljeća“) knjiga je povjesničarke Dagmar Herzog, objavljena 2011. godine u izdanju kuće Cambridge University Press. Dagmar Herzog profesorica je povijesti i znanstvenica na sveučilištu City University of New York, vezana uz zakladu Daniel Rose. Njezini se radovi većim dijelom vežu uz povijest seksualnosti. Najvažnija su joj djela: Sex after Fascism: Memory nad Morality in Twentieth Century Germany (Princeton University Press, 2005.) te Sex in Crisis: The New Sexual Revolution and the Future of American Politics (Basic Books, 2008.).

Ova nadasve originalna knjiga broji pet poglavlja te uvod i epilog. U uvodu (str. 1-5), autorica iznosi tezu da se 20. stoljeće često naziva „stoljećem seksa“ i smatra ga se periodom povećane liberalizacije seksualnih običaja i stavova. Tomu su razlog rastuće usavršavanje i dostupnost kontracepcijskih sredstava, napredak seksualnih prava, veća prihvaćenost predbračnoga seksa, povećana važnost pridana seksu u braku te generalno gledano - uvećano slavljenje seksualnog užitka i pornografije. S druge strane, seksualne politike 20. stoljeća iznimno su komplicirane. Kompliciranost se ogleda u naglim regresijama usmjerenima protiv liberalizacije - nacizmu, fašizmu i staljinizmu, te u rasizmu i bolesti. Prema Herzog, seksualnost je postala ključnim „elementom u procesima sekularizacije i religiozne obnove, glavni pokretač ekonomskog razvoja i locus intenzivnijih pregovora između vlade i građana“. U uvodu autorica donosi i cilj knjige, a taj je iskoristiti temu seksualnosti kao fokus za razmišljanje o širim izazovima s kojima se susreću povjesničari te odgovoriti na pitanje koje su točno veze između ideologija, društvenih uvjeta, tijela, osjećaja i kako su se ti odnosi mijenjali tijekom vremena. Kao temeljni metodološki pristup autorica koristi komparativnu historiju, čijim se alatima služi kako bi opisivanjem sličnosti i razlika te njihovom usporedbom pokazala kompleksnost seksualnosti u 20. stoljeću.

Prvo poglavlje nosi naslov Reconceiving sexuality 1900 - 1914 (str. 6-44). U njemu autorica naznačuje da su krajem 19. stoljeća brojni faktori utjecali na to da seks 
postane važna javna tema. S jedne strane zbog prostitucije, koja je smatrana nadopunom bračnome seksu, ali i koja je bila jedna od glavnih uzročnika širenja veneričnih bolesti u vojsci. Zatim su tu i rastuća želja za kontrolom začeća te izazov koji je postavljen pred heteronormativnost, a ogledao se u homoseksualnim skandalima. Prostitucija je postala zanimljivom zbog pojave pokreta za ženska prava početkom 20. stoljeća, kada je moralna čistoća postala imperativom. Ono što je zanimljivo jest činjenica da u većini europskih država u to vrijeme prostitucija uopće nije bila kriminalizirana. Posebno se razrađuje i pitanje kontracepcije. Početkom 20. stoljeća pojavila se potreba za odvajanjem seksa od reprodukcije te se postavilo pitanje koja je priroda i cilj seksa, odnosno je li prilikom seksualnog čina važna reprodukcija ili seksualni užitak. Također se postavljalo i pitanje emotivnoga i seksualnoga života te njihovo međudjelovanje. Autorica je posvetila dio ovoga poglavlja i djelovanju najvećih seksologa s početka stoljeća, primjerice Magnusa Hirschfelda, koji se zalagao za dekriminalizaciju homoseksualnosti.

Naslov je drugoga poglavlja State intervention 1914 - 1945 (str. 45-95). Ono je posvećeno ratovima i međuratnome periodu te njihovom utjecaju na seksualnost, a u konačnici i na promjene u odnosima među spolovima. Prvi svjetski rat imao je ogroman utjecaj na seksualnost. Dolazi do dramatičnih i brzih promjena u organizaciji i razumijevanju seksualnosti. Isto tako, Prvi je svjetski rat akcelerirao dugoročnije trendove prema većoj jednakosti među spolovima, zato što su žene u velikoj mjeri preuzimale mušku odgovornost. Ulaskom Sjedinjenih Američkih Država u rat na tlu Europe seks je postao transnacionalan. Krajem rata dolazi do sve intenzivnijeg jačanja totalitarnih ideologija, fašizma, nacizma i komunizma, koje su sve za cilj imale represiju seksualnosti. Štoviše, išlo se toliko daleko da se pod utjecajem eugenike odlučivalo kome spolni čin smije služiti za razmnožavanje i prokreaciju. U tim je sustavima homoseksualnost kriminalizirana, a ženske su se uloge svodile na one majke ili domaćice. Autorica je u ovome poglavlju navela niz zakona i godine njihova uvođenja u zemljama Europe. Nasuprot totalitarnim sustavima, autorica spominje Švedsku ili Dansku kao zemlje u kojima su zakoni bili puno liberalniji prema homoseksualnim osobama.

Cold war cultures 1945 - 1965 (str. 96-132) naslov je trećega poglavlja u knjizi. Era Hladnoga rata bila je jedna od najkontradiktornijih era na Zapadu: karakterizirana rastućim prosperitetom, ali i trajnom ambivalentnošću prema užitku kao nečemu što je svrha sebi samome. Skepticizam spram ženskih prava i prava seksualnih manjina bio je sveprisutan. Postojali su tek rijetki aktivisti koji su tražili promjene popularnih stavova i zakona. Rat i njegov neposredni kraj bili su kontekst u kojem su milijuni ljudi iskusili predbračnu i vanbračnu seksualnost i prelazili granice i eksperimentirali u vezama koje nikada ne bi bile moguće u pobliže nadziranim i stabilnim okruženjima gradova u mirno doba. Generalno gledano, autorica tvrdi da bi se o Zapadu u Hladnome ratu mogla izdvojiti dva jaka narativa. Prvi se odnosi na kontinuirani tradicionalizam u rodnim i spolnim vrijednostima, naglašen poslijeratnom restauracijom, koji je bio posebno restriktivan, čak i klaustrofobičan te je zahtijevao strogu heteronormativnost. Drugi se narativ odnosi na priču o ekonomskom i kulturnom optimizmu, većim mogućnostima za konzumerizam, povećanoj aspiraciji za zabavom i početkom ideje romantičnoga modela braka, praćenog povećanom prihvatljivošću 
predbračnog seksa. Te su ambivalentnosti imale za produkt i povećanu liberalizaciju spram seksualnosti u šezdesetim godinama 20. stoljeća.

Četvrto poglavlje nosi naziv Pleasure and rebellion (1965 - 1980) (str. 133-175). To poglavlje autorica počinje rečenicom „Što više vodim ljubav, to više provodim revoluciju“ (str. 133). Ta joj je rečenica polazišna točka za razračunavanje s konceptom seksualne revolucije, fenomenom koji je zahvatio svijest šezdesetih godina prošloga stoljeća te koji je doveo do pojačane teoretizacije, ali i praktične primjene u svakodnevnome životu. Autorica u tome poglavlju obrađuje zemlje kao što su Švedska, Njemačka, Velika Britanija i Francuska te piše o teoretičarima seksualnosti, kao što su Alfred Kinsey ili Wilhelm Reich. Posebna je pažnja posvećena i pitanju abortusa te njegovoj legalizaciji, odnosno kriminalizaciji.

Peto se poglavlje zove Partnerships and practices 1980 - 2010 (str. 176-217). U njemu se autorica bavi pitanjem pojave AIDS-a te suzbijanja te bolesti. Isto tako piše o seksualnosti i njezinoj represiji u socijalističkim sustavima u Europi. Posebno se osvrće na pitanje islama kao novoga neprijatelja Zapada koji propagira represiju seksualnih sloboda. Autorica naglašava i činjenicu da se u suvremeno doba žene kojima se na ultrazvučnome pregledu kaže da im dijete neće biti u potpunosti zdravo više ne potiče na eugenički pobačaj.

Poslije petoga poglavlja slijedi epilog (str. 218-221), u kojemu autorica sumira svoje najvažnije ideje te tvrdi da je 20. stoljeće stoljeće liberalizacije, ali i konflikata vezanih u seksualnost te da je to stoljeće bilo preokupirano seksualnim pitanjima. Knjiga sadrži i ilustracije, čiji se popis nalazi na samome početku knjige, zatim je tu i indeks te zahvale.

Za kraj se usuđujem napisati da je autoričina knjiga remekdjelo posvećeno historiji seksualnosti. Autorica nam daje potpuno novi pogled na turbulentnu povijest seksualnosti u Europi od zalaza viktorijanskog doba do propasti komunizma te uspona europskoga islama. Opća je tendencija nazivati 20. stoljeće „stoljećem seksa“ i na njega gledati kao na eru povećane liberalizacije, no Dagmar Herzog umjesto toga naglašava složenost i kontradikcije u seksualnim željama i ponašanjima, ambivalentnosti koje su obuhvaćale seksualne slobode i teškoće s kojima se susretalo u osiguranju seksualnih prava. Iako je ograničena na Europu, ova knjiga je ipak svjetski primjer kako u istraživanje uklopiti promjenjive sudbine vezane uz brak i prostituciju, kontracepciju i pobačaj te heteroseksualnost i homoseksualnost. Herzog analizira i seksualno nasilje u ratu i miru, promociju seksualnoga zadovoljavanja u fašističkim i demokratskim režimima, ulogu eugenike te fizičke oduzetosti, politizaciju i komercijalizaciju seksa te procese sekularizacije i religiozne obnove. Ipak, zaključno treba navesti njezina tri najveća doprinosa. Prvi je taj što je pokazala zašto su se seksualne kulture u 20. stoljeću mijenjale i u progresivnim i u neotradicionalističkim smjerovima. Drugi je taj što je bacila potpuno novo svjetlo na kompleksne međuveze između seksualne politike i politike općenito. Te treći, i najvažniji, povezala je hetero i homoseksualnu povijest. Stoga je ova knjiga sjajan početak za bavljenjem pitanjem seksualnosti i povjesničarima i sociolozima i antropolozima i etnolozima, ali i svima 
onima koji žele uživati u fluentnome i impresivnom jezičnom stilu autorice koja uz stručno znanje pokazuje i svoju jezičnu kompetenciju na najbolji mogući način.

Zrinka Miljan 